\title{
SCREENING IgM AND IgG ANTIBODIES TO CHLAMYDOPHILA PNEUMONIAE BY ENZYME IMMUNOASSAY (EIA) IN PAEDIATRIC LRTIS IN A TERTIARY HOSPITAL EXPERIENCE IN KOSHI AREA (NORTHERN BIHAR), INDIA
}

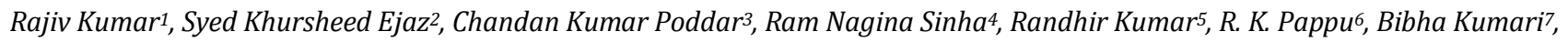
Santosh Kumar ${ }^{8}$

\author{
${ }^{1}$ Assistant Professor, Department of Pathology, Lord Buddha Koshi Medical College, Saharsa. \\ ${ }^{2}$ Assistant Professor, Department of Biochemistry, Lord Buddha Koshi Medical College, Saharsa. \\ ${ }^{3}$ Research Scholar, Department of Microbiology, Indira Gandhi Institute of Medical Sciences, Patna. \\ ${ }^{4}$ Associate Professor, Department of Surgery, Lord Buddha Koshi Medical College, Saharsa. \\ ${ }^{5}$ Senior Resident, Department of Microbiology, Indira Gandhi Institute of Medical Sciences, Patna. \\ ${ }^{6}$ Associate Professor, Department of Microbiology, Lord Buddha Koshi Medical College, Saharsa. \\ 7 Junior Resident, Department of Paediatrics, Lord Buddha Koshi Medical College, Saharsa. \\ sJunior Resident, Department of Paediatrics, Lord Buddha Koshi Medical College, Saharsa.
}

\section{BACKGROUND}

ABSTRACT

Paediatric Lower Respiratory Tract Infections (LRTIs) are a leading cause of mortality and morbidity in children. Chlamydophila pneumoniae (C. pneumoniae) is one of the new emerging infectious agents with a spectrum of clinical manifestations including lower and upper respiratory tract infections.

\section{MATERIALS AND METHODS}

We investigated 100 children of age 5 months to 12 years hospitalised for community-acquired LRT Is with use of serological tests that included solid phase Enzyme-Immunoassays (EIA) for detecting anti-C. pneumoniae immunoglobulin M (IgM) and immunoglobulin G (IgG) antibodies.

\section{RESULTS}

Serological evidence of C. pneumoniae infection was observed in $6(6 \%)$ patients. Specific IgM antibodies were detected in 5 $(83.33 \%)$ of these 6 patients, specific IgM and IgG antibodies were detected in none of the patients, specific IgG antibodies in 1 $(16.66 \%)$ patients and a 4-fold rise in C. pneumoniae antibody IgG titre alone in none of the patients.

\section{CONCLUSION}

This study confirms that C. pneumoniae plays a role in lower respiratory tract infections in Indian children. EIA is feasible and less time consuming method and can be employed for effective treatment and management.

\section{KEYWORDS}

C. pneumoniae, Lower Respiratory Tract Infection, ELISA for IgM/IgG Antibody.

HOW TO CITE THIS ARTICLE: Kumar R, Ejaz SK, Poddar CK, et al. Screening IgM and IgG antibodies to chlamydophila pneumoniae by enzyme immunoassay (EIA) in paediatric LRTIs in a tertiary hospital experience in Koshi area (Northern Bihar), India. J. Evolution Med. Dent. Sci. 2016;5(86):6357-6359, DOI: 10.14260/jemds/2016/1437

\section{BACKGROUND}

Paediatric Lower Respiratory Tract Infections (LRTIs) are a leading cause of mortality and morbidity in children. Chlamydophila pneumoniae (C. pneumoniae) is one of the new emerging infectious agents with a spectrum of clinical manifestations including lower and upper respiratory tract infections.1,2 The majority of C. pneumoniae infections are mild and asymptomatic and is difficult to diagnose. C. pneumoniae does cause serious diseases such as pharyngitis, sinusitis, acute bronchitis and community acquired pneumonia and if

Financial or Other, Competing Interest: None.

Submission 21-09-2016, Peer Review 15-10-2016,

Acceptance 21-10-2016, Published 25-10-2016.

Corresponding Author:

Dr. Chandan Kumar Poddar,

M.Sc. Medical Microbiology,

Ph. D (Students) IGIMS, Patna,

Tutor, Department of Microbiology,

Lord Buddha Koshi Medical College, Saharsa.

E-mail: chandan_microbiology@yahoo.co.in

DOI: $10.14260 /$ jemds/2016/1437 left untreated or undetected these infections can lead to prolonged and persistent disease, a fact documented in recent reports. ${ }^{3}$

\section{MATERIALS AND METHODS \\ Study Design}

A prospective study was designed to evaluate seroprevalence of C. pneumoniae in paediatric Lower Respiratory Tract Infections (LRTIs) in children.

A total of 100 patients were enrolled comprising of fresh clinically diagnosed cases of acute lower respiratory tract infection, admitted to the paediatrics wards of Lord Buddha Koshi Medical College and Hospital, Saharsa, and different Hospital of Saharsa Bihar (India).

\section{Selection of Cases \\ Inclusion Criteria}

Previously healthy male and female children who had been hospitalised for signs and symptoms of paediatric Lower Respiratory Tract Infections (LRTIs) and fulfilling the following criteria were included in this study.

- $\quad$ Children aged 5 months to 12 years. 
- Presence of cough and fever with breathlessness of less than 30 days duration.

- Radiological findings suggestive of consolidation. Bronchopneumonia or interstitial infiltrates with or without hyperinflation.

- Increased respiratory rate (with or without features of respiratory distress) on examination.

- $\quad$ Presence of signs of consolidation or bronchopneumonia with or without wheeze on auscultation.

\section{Exclusion Criteria}

- Hospital acquired pneumonia, i.e. pneumonia that developed 48 hours after hospitalisation or within 7 days of discharge.

- $\quad$ Severe underlying disease.

- $\quad$ Patient was on antibiotics in the past 48 hours preceding enrolment.

The exclusion criteria included hospital-acquired pneumonia, i.e. pneumonia that developed 48 hours after hospitalisation or within 7 days of discharge.

\section{Enrolment and Evaluation of Patients}

Clinical examination was performed in all the children, the details of which were noted in a pre-designed proforma as presence of cough and fever with breathlessness of less than 30 days duration, increased respiratory rate (with/without features of respiratory distress) on examination, presence of signs of consolidation or bronchospasm with/without wheeze on auscultation. After a complete physical examination, the laboratory samples taken at enrolment included blood specimens by Enzyme-Linked Immunosorbent Assay (ELISA) for IgG and IgM antibodies against C. pneumoniae.

\section{Serology}

\section{ELISA for IgM/IgG Antibody to C. pneumoniae}

Commercially available ELISA (Enzyme-linked Immunosorbent assay) technique based kit (Calbiotech Inc., USA) were employed for detecting IgM and IgG antibodies in sera of patients. Tests were performed and results interpreted according to manufacturer's instructions. Diluted patients sera
(Serum diluent contained sorbent to remove the rheumatoid factor and human IgG interference) were added to wells with purified Chlamydophila antigen. IgM/IgG specific antibody, if present got bound to the antigen coated on the microtitre plates. All unbound materials were washed away and the enzyme conjugate was added to bind to the antibody-antigen substrate complex if present. Excess enzyme conjugate was washed off and substrate was added. The plate was incubated to allow the hydrolysis of substrate by enzyme and the intensity of the colour generated was recorded by optical density measurement on an ELISA plate reader.

\section{Test Interpretation Criteria}

ELISA test results for IgG and IgM antibodies were validated as instructed in the manufacturer's instructions insert. The cutoff value was calculated by multiplying the mean optical value of calibrator with the calibration factor (mentioned on the calibrator vial in kit). The antibody index of test sample was determined by dividing the optical density value of each sample by the cut-off value.

\section{RESULTS}

\section{Demographic Profile}

There were $64(64 \%)$ males and $36(36 \%)$ in the 100 cases investigated. In totality, 64 (64\%) were aged 0 to 1 yrs. (Group 1), 24 (24\%) aged group 2 to 5 yrs. (Group 2) and 12 (12\%) were aged 6-15 (Group 3). On statistical evaluation of the three age groups, i.e. Group 1 vs. Group 2 vs. Group 3, a p value of 0.05 which was borderline significant.

The presence of C. pneumoniae antibody was higher in males $5(7.87 \%)$ than in females $1(2.74 \%)$, though this was statistically not significant (Table 1 and 2).

\section{Serological Profile}

Serological evidence of C. pneumoniae infection was observed in $6(6 \%)$ patients: specific IgM antibodies (serum dilution $1: 100)$ in a standalone test in acute phase were detected in 5 $(83.33 \%)$ patients; specific IgM and specific IgG antibodies in acute phase specimens were detected in none of the patients and specific IgG antibodies in both acute and paired sera in one case $(16.55 \%)$.

\begin{tabular}{|c|c|c|c|c|}
\hline Sex & Total (n=100) & C. pneumoniae Antibody +ve (n= 6) & C. pneumoniae Antibody -ve (n=94) & p value \\
\hline & No. (\%) & No. (\%) & No. (\%) & 0.22 \\
\hline Males & $64(64.00)$ & $5(83.33)$ & $87(92.55)$ & NS \\
\hline Females & $36(36.00)$ & $1(16.55)$ & $91(96.80)$ & $\mathbf{9 4}(100)$ \\
\hline Total & $\mathbf{1 0 0 ( 1 0 0 )}$ & $\mathbf{4 ( 1 0 0 )}$ & Table 1. Sex Distribution in 100 Children with LRTIs in Koshi Area of Bihar \\
\hline \multicolumn{4}{|c}{} \\
\hline
\end{tabular}

NS - Not significant.

\begin{tabular}{|c|c|c|c|}
\hline Age Group & Total (n=100) & C. pneumoniae +ve & C. pneumoniae -ve \\
\hline & No. (\%) & No. $(\%)$ & No. $(\%)$ \\
\hline $0-1$ yrs. & $64(64.00)$ & 2 & 21 \\
\hline $2-5$ yrs. & $24(24.00)$ & 3 & 11 \\
\hline $6-12$ yrs. & $12(12.00)$ & 1 & 94 \\
\hline Total & $100(100 \%)$ & 06 & \\
\hline \multicolumn{3}{|c|}{ Table 2. Age Distribution in Study Group in Koshi Area of Bihar } \\
\hline
\end{tabular}

\section{Statistical Evaluation}

- $\quad$ Age groups 0-1 years vs. 2-5 years: $p=0.24$

- $\quad$ Age groups 2-5 years vs. 6-15 years: $p=0.71$

- Overall: Group 1 vs. Group 2 vs. Group 3: $p=0.05$ (Significant). 


\section{DISCUSSION}

Laboratory tests of Chlamydophila infections have included isolation in cell culture, direct detection of Chlamydia antigen by Direct Fluorescent Antibody (DFA), Enzyme Immunoassay (EIA), by DNA-RNA probes, Polymerase Chain Reaction (PCR) and the Ligase Chain Reaction (LCR). The Microimmunofluorescence (MIF) technique is a method of choice for diagnosing acute $\mathrm{C}$. pneumoniae infection, but no method of microbiological diagnosis at acute Chlamydophila infection is ideal, because the organism grows poorly on cell culture which is also cumbersome to perform.

Evaluations on commercial ELISA kits and microimmunofluorescence (Reference method) to screening C. pneumoniae IgG have documented that C. pneumoniae EIA test demonstrated good concordance with the MIF test. EIA holds the most promise and has several advantages including high thoughtput, objective endpoints, technical accessibility and an electronic record of results. Evaluations of these kits have however reported problems with both sensitivity and specificity. ${ }^{4}$

Western studies that examined the role of C. pneumoniae in lower respiratory tract infections in paediatric populations found evidence of infection in 0 to $18 \%$ cases, the variation being attributed to varied serologic methods and diagnostic serologic criteria used therein.5,6-8 Indian studies on this subject are scattered, conducted on low populations and have employed different methods of diagnosis of this infection.9,10 In our study, 5.5 (5.5\%) documented anti-C. pneumoniae IgM antibody spread across all age groups and a borderline significant $(\mathrm{p}=.05)$ statistical valuation was arrived at when the three age groups were compared for the presence of antiC. pneumophila antibodies. While investigating the role of Chlamydophila species in respiratory infections in children under 5 years of age employing antigen detection by Direct Immunofluorescence (DIF) and anti-Chlamydia immunoglobulin IgG by the enzyme immunoassay, wherein cut-off titres were employed to differentiate present and past C. pneumoniae infection, $30 \%$ children with lower respiratory tract infection that were less than 5 years of age, documented anti-C. pneumoniae IgG antibodies by solid phase ELISA in comparison to our finding of $0.5 \%$. Exclusion of children below six months of age, in that study in contrast to our study may perhaps explain this discrepancy.

The differential presence of C. pneumoniae antibodies was statistically insignificant when compared to male and female children in the cases investigated. Also, male cases far outnumbered female cases as far as the total 100 case group investigated was concerned.

In the present study $88(88.00 \%)$ cases investigated as follows in the age group less $0-5$ years and most of them i.e. 64 $(64.00 \%)$ were in the age group $0-1$ years. Taking this into perspective along with the fact that previous studies have adopted different methods (most often MIF test) for C. pneumoniae diagnosis, making a strict comparison of age related prevalence of $\mathrm{C}$. pneumoniae may not be possible since ours was a random study with a disproportionately large case numbers in the age group of 0-1 year. Other serological surveys have documented rising C. pneumoniae antibody prevalence in school going children that have reached up to $30-45 \%$ in adolescents, while in children under 5 years of age anti-C. pneumoniae antibody prevalence has varied from nil to rare, though in one study on Filipino children with lower respiratory tract infection acute or chronic antibodies were detected in nearly $10 \%$ cases. $^{11}$
One C. pneumoniae antibody positive case, simultaneously documented anti-M. pneumoniae IgM antibodies suggesting probable co-infection. M. pneumoniae and C. pneumoniae coinfections are not rare, but its clinical implications are unclear. Questions as to whether one pathogen facilitates penetration of other, whether both cause the respiratory tract infection or whether combination of both lead to a more severe infection remain unanswered. ${ }^{12}$

\section{CONCLUSION}

This study confirms that C. pneumoniae plays a role in lower respiratory tract infections in Indian children. EIA is feasible and less time consuming method and can be employed for effective treatment and management.

\section{REFERENCES}

1. Marrie TJ, Grayston JT, Wang S, et al. Pneumonia associated with TWAR strain of chlamydia. Ann Int Med 1987;106(4):507-11.

2. Hermann B, Salih MAM, Yousif BE, et al. Chlamydial etiology of acute lower respiratory tract infections in children in the sudan. Acta Pediatrica 1994;83(2):169-72.

3. Kutlin A, Tsumura N, Emre $U$, et al. Evaluation of chlamydia immunoglobulin M (IgM), IgG, and IgA rELISAs medac for diagnosis of chlamydia pneumoniae infection. Clin Diagn Lab Immunol 1997;4(2):213-6.

4. Dowell SF, Peeling WR, Boman J, et al. Standardizing chlamydia pneumoniae assays: recommendations from the centers for disease control and prevention (USA) and the laboratory center for disease control (Canada). Clin Infect Dis 2001;33(4):492-503.

5. Thom DH, Grayston JT, Wang SP, et al. Chlamydia pneumoniae strain TWAR, mycoplasma pneumoniae, and viral infection in acute respiratory disease in a university student health clinic population. Am J Epidemiol 1990;132(2):248-56.

6. Somer A, Salman N, Yalsin I, et al. Role of mycoplasma pneumoniae and chlamydia pneumoniae in children with community acquired pneumonia in istambul, Turkey. J Trop Ped 2006;52(3):173-8.

7. Grayston JT, Campbell LA, Kuo CC, et al. A new respiratory tract pathogen: chlamydia pneumoniae strain TWAR. J Infect Dis 1990;161(4):618-25.

8. Clements H, Stephenson T, Gabriel V, et al. Rationalized prescribing for community acquired pneumonia. A closed loop audit. Arch Dis Child 2000;83:320-4.

9. Chaudhry R, Nazima N, Dhawan B, et al. Prevalence of mycoplasma pneumoniae and chlamydia pneumoniae in children with community acquired pneumonia. Indian J Pediatr 1998;65(5):717-21.

10. Pandey A, Chaudhry R, Kapoor L, et al. Acute lower respiratory tract infection due to chlamydia in children under five years of age. Indian J Chest Allied Sci 2005;47:97-101.

11. Ruutu SP, Leinonen $P$, Panelius $M$, et al. Acute lower respiratory tract infection associated with chlamydial TWAR antibody in filipino children. J Infect Dis 1988;158(5):1095-7.

12. Principi N, Esposito S, Blasi F, et al. Role of mycoplasma pneumoniae and chlamydia pneumoniae in children with community-acquired lower respiratory tract infections. Clin Infect Dis 2001;32(9):1281-9. 